\title{
Transvaginal Natural Orifice Translumenal Endoscopic Surgery (TVNOTES): Concerns of Gynaecology Outpatients in a Tertiary Care Centre*
}

\author{
Renita Lobo" ${ }^{1}$, Kannavi Jayashree ${ }^{2}$, Annamma Thomas², Santosh A. Olakkengil ${ }^{1 \#}$ \\ ${ }^{1}$ Department of Surgery, St John's Medical College Hospital, Bangalore, India \\ ${ }^{2}$ Department of Obstetrics \& Gynaecology, St John’s Medical College Hospital, Bangalore, India \\ Email: \#olakkengil@gmail.com
}

Received October 4, 2012; revised November 7, 2012; accepted November 21, 2012

Copyright (C) 2013 Renita Lobo et al. This is an open access article distributed under the Creative Commons Attribution License, which permits unrestricted use, distribution, and reproduction in any medium, provided the original work is properly cited.

\begin{abstract}
Objective: (TVNOTES) [1], currently the most popular of the NOTES procedures being performed, offers the safest access point while avoiding a breach in the gastrointestinal tract to gain intraperitoneal access. But are women ready to embrace TVNOTES? Although similar studies have been conducted in developed nations, the authors aimed to seek the opinions of Indian women towards TVNOTES. Design: This study presents the results of a survey on attitudes of Indian women towards TVNOTES. 300 women attending a gynaecology out patients' clinic were administered a questionnaire which sought out the percentage of Indian women concerned with surgical scars, their preference between TVNOTES and conventional laparoscopic surgery and apprehensions towards the vagina being used as an entry site for surgery. Results: $85.67 \%$ of the participants opted for scarless intra-abdominal surgery. Upon revealing that the surgery would be performed transvaginally (TV), reservations were unveiled, with $67.33 \%$ of all respondents being either unhappy or unsure about undergoing TV surgery. Results were initially equivocal when asked to choose between TVNOTES and conventional laparoscopic surgery, but when informed that TVNOTES may be as safe and efficacious as conventional laparoscopic surgery, the scales tipped in favour of TVNOTES, with three-fourths of the respondents opting for the latter. Conclusions: Although TVNOTES has captured the imagination and attention of surgeons, existing data suggest that the beneficiaries (i.e. women) remain to be convinced. This study suggests that Indian women will embrace TV surgery once its safety is proven, improved cosmesis being a predominant factor in making this choice.
\end{abstract}

Keywords: Giant Hemangioma; Liver Transplant; Case Report

\section{Introduction}

"Big surgeons make big incisions"-the old adage has been rendered redundant by the advent of laparoscopic surgery into the realm of operative surgical techniques barely two decades ago. The next frontier is that of the natural orifice translumenal endoscopic surgery (NOTES [2]) which proposes what seems impossible-scarless surgery. As expected, NOTES has captured everyone's attention ever since Kalloo, in 2004, demonstrated that transgastric peritoneoscopy is feasible [3,4], promoting further research and discovery including NOTES gall bladder surgery [5,6], appendectomy, splenectomy [7], gastrojejunostomy [8], abdominal lymphadenectomy and even NOTES nephrectomy $[9,10]$. NOTES comes with a

\footnotetext{
*Author Disclosure Statement: The authors have neither conflicts of interest nor financial ties to disclose.

${ }^{\#}$ Corresponding author.
}

barrage of advantages including the possibility of reduced post-operative pain, faster recovery and healing time, shorter hospital stays, better post-operative pulmonary and diaphragmatic functions [11,12] and potentially even decreasing the incidence of incisional hernias. Being a novel technique, NOTES still has some unaddressed issues such as the best technique to close the translumenal access points, maintenance of intraperitoneal pressures, the recognition and control of intraprocedural complications, suitable removal of resected organs, design of procedure specific instruments [13], possibility of higher anastomotic leaks [14] and higher cost of the procedure. Most of the roadblocks parallel the ones conventional laparoscopy faced at its advent [15].

Although transvaginal access to the peritoneal cavity made its appearance three years after the advent of NOTES [16], this route offers the safest access point, the 
smallest learning curve and the greatest advantage of avoiding creating a breach in the gastrointestinal tract to gain access to the intraperitoneal cavity, thus making it account for the majority of NOTES procedures to date [17]. Thus, the feasibility of TVNOTES has been proven and made its due headlines, what hasn't; however, is the opinion of women towards this procedure. Even with initial reports of the safety and efficacy of transvaginal cholecystectomy, patients have not been forthcoming and seem to have reservations with undergoing such a procedure [18]. There have been a few similar studies, based in developed nations $[1,19]$. With NOTES having some of its first successful footing in India [20], are Indian women likely to embrace TVNOTES? This study aims to answer this.

\section{Materials and Methods}

The opinion of females attending an obstetrics and gynaecology out patients' clinic in a tertiary care centre in South India towards TVNOTES was sought over a 5 months period, using a 13-point questionnaire designed by a multidisciplinary group of surgeons. The questionnaire was administered by medical staff, ensuring that participants understood the procedure and the questions and queries were addressed, in a language understood by the participants. Ethical approval for the study was granted by the local Research and Ethics Committee. The results were tabulated and analysed using Stata/IC (version 12.0).

\section{Results}

In this study, 300 females were administered the questionnaire, and the results analysed. Majority of the participants were in the 25 - 40 years age group (43\%, $n=$ 129) and the same percentage of participants were parous. $33.67 \%$ of the participants had undergone a previous abdominal surgery and another 3.3\% had undergone a hysterectomy.

All participants, irrespective of previous exposure to surgery were asked about their opinion on surgical scars. $47 \%(n=141)$ did mind abdominal scars and when divided according age, 39\% of participants in the 18 - 25 years age group, $44.68 \%$ of the 25 - 40 years age group and $16.3 \%$ of the $>40$ years age group said they did mind abdominal surgical scars.

$85.67 \%(n=257)$ opted for scarless surgery, majority of whom were in the 25 - 40 years age group $(42.4 \%, \mathrm{n}=$ $109)$. Of these, $44.67 \%(n=134)$ opted for scarless surgery citing a combination of cosmetic benefit and the potential for less post-operative pain as possible advantages while $27.33 \%(n=82)$ opted for scarless surgery for cosmetic benefit alone. $55.33 \%$ of the participants who had initially said that they did not mind surgical scars opted for scarless surgery when offered.

The respondents were then asked how they would feel if the vagina were to be used as the entry point for such a surgery. 29\% were unhappy or very unhappy at this prospect, the majority (38.33\%, $n=115$ ) being unsure and $32.6 \%$ being happy or very happy at this prospect.

When questioned regarding concerns of negative sexual impact after TVNOTES 40\% were unsure while $37.7 \%$ were not concerned (51.33\% in the 25 - 40 years age group).

Finally, participants were asked to choose between a conventional laparoscopic surgery and TVNOTES. $49.66 \%$ opted for conventional laparoscopic surgery. But after being informed that TVNOTES is potentially as safe and effective as the conventional laparoscopic surgery, 78.26\% opted for TVNOTES. 50.84\% of the respondents would prefer a female surgeon to operate if they needed to undergo TVNOTES. $62.67 \%$ of parous respondents opted for TVNOTES even before being told of the potential safety and efficacy of the procedure indicating that parity may have relation to how comfortable a patient may feel to undergo a transvaginal procedure. $35.33 \%$ of those who had undergone a previous abdominal surgery opted for TVNOTES before knowing the potential for safety or efficacy of the procedure.

\section{Discussion}

TVNOTES, the safest and most feasible of the NOTES procedures, is also the most commonly performed NOTES procedure currently [15]. Before TVNOTES becomes a mainstream surgical procedure, it has numerous barriers it needs to break, and one such barrier is the public's perception and acceptance of the procedure.

India constitutes a large percentage of the world's population and improvements in surgical techniques resulting in fewer post-operative complications, shorter hospital stays and faster recovery stand to benefit many. In addition, the national ensemble, the saree, reveals a portion of bare abdomen and thus, perhaps, Indian women seem more averse to abdominal surgical scars as indicated in this study where $47 \%$ of the participants said that they did mind abdominal scars as opposed to $34 \%$ in a similar study conducted by the same author on Australian women [1]. On the same note, $85.67 \%$ of the Indian participants opted for scarless surgery when offered.

Women's inhibitions to TVNOTES was apparent when $67.33 \%$ of the participants said they were either unsure or unhappy about the prospect of the vagina being used as an entry site for surgery even though only $22 \%$ of the respondents seemed concerned about the possibility of a negative sexual impact post procedure, majority (83.58\%) of whom were $<40$ years of age. But when proposed that TVNOTES may be as safe and efficacious as the conventional laparoscopic surgery, with the added advantage 
of being a scarless procedure and potentially less painful, $78.26 \%$ opted for TVNOTES. This is in contrast to the $65 \%$ of Australian women who preferred to adhere to the conventional laparoscopic procedure [1]. Again contrasting their Australian counterparts, 50.84\% of the Indian respondents preferred a lady surgeon while only $17 \%$ of the Australian respondents had surgeon preferences [1]. Concerns were raised about the costs of the procedure and possibility of injury to reproductive organs and vaginal scarring and the impact on fertility. As sample sizes in most studies are inadequate currently to address these concerns, with time most will be answered.

Thus, Indian women embraced the concept of scarless surgery and though unhappy at the prospect of transvaginal NOTES, would still opt for the latter if proven that TVNOTES is as safe and effective as conventional laparoscopic surgery and would be more comfortable if the operating surgeon is a woman.

\section{Acknowledgements}

The authors acknowledge Mrs. Tinku Sarah for her valuable assistance in data collation:

\section{REFERENCES}

[1] S. A. Olakkengil, A. D. Strickland, M. G. A. Norwood, F. B. Willison and P. J. Hewett, "Transvaginal Natural Orifice Translumenal Endoscopic Surgery (NOTES): A Survey of Women's Views on a New Technique," Surg Endoscopy, Vol. 24, No. 10, 2010, pp. 2424-2431. doi:10.1007/s00464-010-0968-3

[2] D. Rattner and A. Kalloo, “ASGE/SAGES Working Group on Natural Orifice Translumenal Endoscopic Surgery," Surgical Endoscopy and Other Interventional Techniques, Vol. 20, No. 2, 2006, pp. 329-333. doi:10.1007/s00464-005-3006-0

[3] A. N. Kalloo, S. V. Kantsevoy, V. K. Singh, et al., "Flexible Transgastric Peritoneoscopy: A Novel Approach to Diagnostic and Therapeutic Interventions in the Peritoneal Cavity [Abstract]," Gastroenterology, Vol. 118, No. 4, 2000, p. A1039. doi:10.1016/S0016-5085(00)86305-2

[4] A. N. Kalloo, V. K. Singh, S. B. Jagannath, et al., "Flexible Transgastric Peritoneoscopy: A Novel Approach to Diagnostic and Therapeutic Interventions in the Peritoneal Cavity," Gastrointestinal Endoscopy, Vol. 60, No. 1, 2004, pp. 114-117. doi:10.1016/S0016-5107(04)01309-4

[5] P. O. Park, M. Bergstrom, K. Ikeda, et al., "Experimental Studies of Transgastric Gallbladder Surgery: Cholecystectomy and Cholecystogastric Anastomosis (Videos)," Gastrointestinal Endoscopy, Vol. 61, No. 4, 2005, pp. 601-606. doi:10.1016/S0016-5107(04)02774-9

[6] C. Rolanda, E. Lima, J. M. Pego, et al., "Third-Generation Cholecystectomy by Natural Orifices: Transgastric and Transvesical Combined Approach (with Video)," Gastrointestinal Endoscopy, Vol. 65, No. 1, 2007, pp.

\section{1-117. doi:10.1016/j.gie.2006.07.050}

[7] S. V. Kantsevoy, B. Hu, S. B. Jagannath, et al., "Transgastric Endoscopic Splenectomy. Is It Possible?” Surgical Endoscopy and Other Interventional Techniques, Vol. 20, No. 3, 2006, pp. 522-525. doi:10.1007/s00464-005-0263-X

[8] S. V. Kantsevoy, S. B. Jagannath, H. Niiyama, et al., "Endoscopic Gastrojejunostomy with Survival in a Porcine Model,” Gastrointestinal Endoscopy, Vol. 62, No. 2, 2005, pp. 287-292. doi:10.1016/S0016-5107(05)01565-8

[9] R. V. Clayman, G. N. Box, J. B. A. Abraham, et al., "Rapid Communication: Transvaginal Single-Port NOTES Nephrectomy: Initial Laboratory Experience,” Journal of Endourology, Vol. 21, No. 6, 2007, pp. 640-644.

[10] S. A. Olakkengil, et al., "Evolution of Minimally Invasive Surgery for Donor Nephrectomy and Outcomes," Journal of the Society of Laparoendoscopic Surgeons, Vol. 15, No. 2, 2011, pp. 208-212. doi:10.4293/108680811X13071180406637

[11] Y. W. Novitsky, K. W. Kercher, D. R. Czerniach, G. K. Kaban, S. Khera, K. A. Gallagher-Dorval, M. P. Callery, D. E. M. Litwin and J. J. Kelly, "Advantages of MiniLaparoscopic vs Conventional Laparoscopic Cholecystectomy-Results of a Prospective Randomized Trial," Archives of Surgery, Vol. 140, No. 12, 2005, pp. 11781183. doi:10.1001/archsurg.140.12.1178

[12] S. Perretta, P. Allemann, M. Asakuma, B. Dallemagne and J. Marescaux, “Adrenalectomy Using Natural Orifice Translumenal Endoscopic Surgery (NOTES): A Transvaginal Retroperitoneal Approach,” Surgical Endoscopy, Vol. 23, No. 6, 2009, p. 1390.

[13] D. Rattner and A. Kalloo, "ASGE/SAGES Working Group on Natural Orifice Translumenal Endoscopic Surgery," Surgical Endoscopy and Other Interventional Techniques, Vol. 20, No. 2, 2006, pp. 329-333. doi:10.1007/s00464-005-3006-0

[14] M. F. McGee, J. M. Marks, R. P. Onders, A. Chak, J. Jin, C. P. Williams, S. J. Schomisch and J. L. Ponsky, "Complete Endoscopic Closure of Gastrotomy after Natural Orifice Translumenal Endoscopic Surgery Using the NDO Plicator," Surgical Endoscopy, Vol. 22, No. 1, 2008, pp. 214-220. doi:10.1007/s00464-007-9565-5

[15] A. A. Gumbs, D. Fowler, L. Milone, J. C. Evanko, A. O. Ude, P. Stevens and M. Bessler, "Transvaginal Natural Orifice Translumenal Endoscopic Surgery Cholecystectomy-Early Evolution of the Technique," Annals of Surgery, Vol. 249, No. 6, 2009, pp. 908-912. doi:10.1097/SLA.0b013e3181a802e2

[16] J. Marescaux, B. Dallemagne, S. Perretta, A. Wattiez, D. Mutter and D. Coumaros, "Surgery without Scars: Report of Transluminal Cholecystectomy in a Human Being," Archives of Surgery, Vol. 142, No. 9, 2007, pp. 823-827. doi:10.1001/archsurg.142.9.823

[17] M. C. Meadows and R. S. Chamberlain, “A Review on the Status of Natural Orifice Transluminal Endoscopic Surgery (NOTES) Cholecystectomy: Techniques and Challenges," Open Access Surgery, Vol. 2010, No. 3, 2010, pp. 73-86. doi:10.2147/OAS.S7300

[18] T. Sharples, “The No Incision Appendectomy, Time 
Health,” 2008. www.time.com/time/health/article/0,8599,1727656,00.ht $\mathrm{m}$

[19] S. A. Olakkengil, M. G. Norwood, A. D. Strickland, F. Behnia-Willison, M. Mohan Rao and P. J. Hewett, "Perspec- tives of Laparoscopic Donors toward a New Procedure: Transvaginal Donor Nephrectomy," Journal of
Laparo- endoscopic \& Advanced Surgical Techniques, Vol. 20, No. 10, 2010, pp. 803-806.

doi:10.1089/lap.2010.0291

[20] N. Reddy and P. Rao, "Per Oral Transgastric Endoscopic Appendectomy in Human," 45th Annual Conference of the Society of Gastrointestinal Endoscopy of India, Jaipur, 28-29 February 2004.

\section{Appendix: Questionnaire}

Background:

Key hole (laparoscopic) surgery using small incisions, is a well-established technique. However, there is now a new concept in surgery known as "NOTES" (Natural Orifice Translumenal Endoscopic Surgery). This utilises a natural orifice (e.g. the vagina) to allow entry into the abdominal cavity so that operations such as oophorectomy (removal of the ovary) can be performed with the use of specialised equipment, leaving no visible scars. It may also be potentially less painful. In a few specialist centres, this procedure is now being performed although there are no clinical trials to support its use. As a woman, we would be interested to hear your views regarding the utilisation of the vagina as a way of performing this type of surgery.

1. Age: years

2. Have you had children? Y/N

3. Have you had a hysterectomy? Y/N

4. Did you undergo laparoscopic or open hysterectomy?

a) Laparoscopic

b) Open

c) Not applicable

5. Have you had an abdominal operation before? Y/N

6. Would you mind abdominal scars as part of an abdominal operation? Y/N

7. Would you find it preferable if you could have the operation (laparoscopic oophorectomy), using an alternative method resulting in no scars? $\mathrm{Y} / \mathrm{N}$

If yes, is this because of:

a) Cosmetic reasons

b) Potential for less pain

c) Both

d) Other (please state)

8. How do you feel about using the vagina as an entry site for an operation?
a) Very happy
b) Happy
c) Not sure

d) Unhappy

e) Very unhappy

9. Would you be concerned that surgery through the vagina (NOTES) may have a negative impact on your sexual function?

a) Yes

b) No

c) Not sure

10. Would you prefer to have a laparoscopic (key hole) oophorectomy or a NOTES oophorectomy?

a) Laparoscopic oophorectomy

b) NOTES oophorectomy

11. If NOTES oophorectomy was shown to be as effective and as safe as laparoscopic oophorectomy which would you prefer?

a) Laparoscopic oophorectomy

b) NOTES oophorectomy

12. If you required a gynaecological procedure such as oophorectomy, how would you feel about this being performed vaginally using NOTES, rather than with standard key hole surgery which is performed by making small incisions through your abdomen?
a) Very happy
b) Happy
c) Not sure
d) Unhappy
e) Very unhappy

13. Finally, would the sex of the surgeon influence your decision as to whether to undergo a NOTES procedure?
a) Yes
b) No
c) Unsure 